\title{
O estabelecimento da tradição de investigação mendeliana sob a perspectiva epistemológica de Larry Laudan
}

\section{The establishment of mendelian research tradition in the epistemological perspective of Larry Laudan}

DOI: $10.46814 /$ lajdv2n5-001

Recebimento dos originais: 10/07/2020

Aceitação para publicação: 30/08/2020

\author{
Guilherme Kunde Braunstein \\ Doutorando em Educação em Ciências pela Universidade Federal do Rio Grande do Sul -UFRGS \\ Instituição: Universidade Estadual do Rio Grande do Sul -Uergs \\ Endereço: Av. Antônio Ribeiro Branco, 1060, bairro Parque dos Rodeios, Vacaria - RS, Brasil \\ E-mail: zeneffi@gmail.com
}

\begin{abstract}
RESUMO
Este trabalho tem por objetivo apresentar aos leitores alguns aspectos da epistemologia de Larry Laudan, contextualizando seu ponto de vista de que a ciência avança por meio da resolução de problemas. Usa-se para tanto a história de Gregor Mendel como um exemplo da aplicação dos conceitos de problema e tradição de investigação. São apresentados também diversos fatores que poderiam ter motivado, e até justificado, o esquecimento do mendelismo por mais de 30 anos, incluindo seu conflito conceitual com o darwinismo. Apontam-se, por fim, alterações pelas quais estas duas tradições foram obrigadas a passar até o estabelecimento da teoria sintética, aceita atualmente. Concluindo-se que a epistemologia de Laudan possibilita a explicação das alterações vivenciadas ao longo do mendelismo.
\end{abstract}

Palavras-chave: Larry Laudan, Mendel, tradição de investigação, história da biologia

\begin{abstract}
This paper has the objective to present to the readers some aspects of the Larry Laudan epistemology, contextualizing his viewpoints that the science advance through the resolution of problems. Its used for this the history of Gregor Mendel as an example of the application of problem and tradition of research concepts. Are also presented several factors that might have motivated and justified the forgetfulness of Mendelism by more than 30 years, including its conceptual conflict with Darwinism. Finally are pointed changes by which these two traditions have been forced to has, for the establishment of the synthetic theory, currently accepted. It concluding with this, that the epistemology of Laudan is a good option to explain the changes experienced over Mendelism.
\end{abstract}

Keywords: Larry Laudan, Mendel, research tradition, history of biology 


\section{INTRODUÇÃO}

Um dos acontecimentos mais relevantes na história da biologia é o trabalho do abade Gregor Mendel sobre hereditariedade. Sua relevância histórica se deve a singularidade de sua descoberta, ocorrida ainda 30 anos antes de a comunidade científica estar preparada tanto para aceitá-la, quanto para compreender seu real valor. Na tentativa de explicar o motivo de sua não aceitação, por parte de seus contemporâneos, diversas perspectivas tem sido utilizadas. Dentre essas as posições mais comuns são a do conflito com a tradição darwinista, o que teria ofuscado a descoberta de Mendel (conflito que permaneceu até 1935 com a formulação da teoria sintética [Freire-Maia, 1995]), e a ideia de que a linguagem e método de sua pesquisa não eram condizentes com os padrões da época (Leite et al, 2001). Uma outra justificativa para este período de esquecimento está na afirmação de que o mendelismo, tal como o conhecemos, pouco se relacionaria com os achados originais de Mendel, sendo na realidade uma redescoberta que contou com muitos fatores diferentes das suas proposições originais (Allen, 2003).

A rejeição das propostas de Mendel por parte dos cientistas de sua época pode ser compreendida como algo racional ao se adotar a perspectiva do epistemólogo Larry Laudan de como a ciência se desenvolve. Suas proposições permitem analisar a tradição mendeliana com relação ao seu potencial de resolver problemas e ainda instrumentaliza a comparação das tradições de investigação darwinianas e mendelianas de modo racional e progressivo, justificando desta maneira a escolha do darwinismo em detrimento a teoria de Mendel.

\section{TRADIÇÃO DE INVESTIGAÇÃO EM LAUDAN}

O epistemólogo e físico Larry Laudan é autor de uma das teorias mais promissoras na explicação do processo pelo qual ocorre o desenvolvimento do conhecimento científico (não se restringindo às Ciências Naturais). Isso ocorre por duas razões principais: em primeiro lugar por sua ênfase na importância dos problemas conceituais, questões que para epistemólogos como Popper (2007) seriam taxadas de psicologismo ou questões metafísicas e, portanto, não analisáveis; em segundo lugar por sua epistemologia instrumentalizar a comparação de conjunto de teorias diferentes e até rivais, permitindo a identificação do conjunto mais promissor a ser seguido.

Tais assuntos são amplamente desenvolvidos no livro "Progress and Its Problems", publicado em 1977 e traduzido para o espanhol em 1986 sob o título "El progreso y sus problemas". Nesta obra (que será usada como referência para os parágrafos subseqüentes) Laudan adota como tema central e meta das ciências a resolução de problemas. Uma vez que sua obra é extensa, discutir-se-á apenas as partes mais relevantes para a compreensão da história de Mendel, tendo por foco principal as tradições de investigação. 
$\mathrm{Na}$ busca pela resolução de problemas, na visão de Laudan, é possível que diferentes tradições se desenvolvam concomitantemente. Isso permite o estabelecimento de uma disputa entre elas, na qual a tradição que melhor resolver os problemas que lhe são propostos, gerando o mínimo possível de anomalias, será uma forte candidata a ser seguida por sua maior racionalidade.

Existem dois conceitos chave para que se compreenda a argumentação de Laudan: o primeiro deles é o de "problema" e o segundo o de "tradição de investigação". Por problema entende-se a questão empírica ou conceitual que questiona o funcionamento de uma teoria, sendo os problemas empíricos os mais fundamentais, portanto, classificados como de primeira ordem; enquanto que os conceituais, que são mais complexos por serem dependentes dos empíricos, são considerados problemas de segunda ordem. De modo geral cada um destes problemas pode ser tratado por uma teoria que irá enquadrá-los em três estados: "resolvido" (no caso de a teoria justificar sua ocorrência); "não resolvido" (quando nenhuma teoria é capaz de justificá-lo); ou "anômalo" (quando a teoria em questão não o justifica, mas uma rival o faz).

Uma tradição de investigação, por sua vez, pode ser definida da seguinte maneira:

Uma tradição de investigação é um conjunto de suposições gerais acerca das entidades e processos de um âmbito de estudo, e acerca dos métodos apropriados que devem ser utilizados para investigar os problemas e construir as teorias desse domínio. (Laudan, 1986, p.116 [tradução minha])

Essas tradições servem como fundamento e guia para as linhas individuais de pesquisa, fornecendo bases em comum tanto de ordem ontológica, referindo-se as crenças e visões de mundo que o grupo compartilha, quanto metodológica, referindo-se aos métodos experimentais ou analíticos aceitos pelo grupo. A tradição fornece também uma audiência primária para os pesquisadores que a seguem.

Faz-se necessário desde já uma distinção fundamental entre as tradições e as teorias que as compõem. A tradição é a entidade que define como o pesquisador deve proceder ao desenvolver suas teorias, é um acordo entre uma determinada comunidade sobre o que pode ou não ser aceito em termos de crenças e métodos, definindo como os elementos teóricos podem se relacionar. Ela possui um caráter mais conceitual, motivo pelo qual não é corroborável, falseável, refutável e nem tem caráter explicativo. Por outro lado, as teorias imperativamente se dispõem e resolver problemas empíricos ou conceituais, sendo, portanto, testáveis, falseáveis, corroboráveis e refutáveis.

Apesar das características que as distinguem, teoria e tradição se relacionam fortemente e de modo, por vezes, até irracional. Dessa maneira uma teoria, apesar de questionável, pode ser aceita por grande parte do corpo científico, caso seja sustentada por uma tradição forte. Assim como uma teoria forte pode ser menosprezada soberbamente, caso seja oriunda de uma tradição não bem 
conhecida ou conceituada.

A abordagem de resolução de problemas é particularmente eficaz por permitir a avaliação do progresso de tradições distintas, análise que é considerada impossível para outros epistemólogos racionalistas, como Popper (2007), seja pela não equivalência das proposições, ou pela incompatibilidade lingüística. $\mathrm{O}$ argumento que permite a comparação em Laudan é o de que tanto a capacidade de resolver problemas, quanto os fatores internos da tradição (grau de corroboração, precisão, simplicidade, coerência e consistência) são unidades mensuráveis para cada tradição de investigação, permitindo desta forma que se descubra qual delas é a mais progressista, e qual resolve melhor os problemas, para com isso se escolher de modo racional a melhor a ser seguida.

As tradições podem se desenvolver de duas formas distintas: a primeira delas por meio de mudanças em suas teorias subordinadas; e a segunda por meio de alterações no núcleo da tradição, ou seja, nos conceitos fundamentais desta. Estas mudanças são incorporadas à tradição de modo lento e gradual, mais pela adição de teorias ad hoc do que propriamente por revoluções. Isso permite a convivência e concorrência de uma infinidade de tradições rivais, o que possibilita o exame comparativo das suas diferentes teorias que se propõem a resolver problemas em comum. Por meio destas comparações e acréscimos ad hoc uma tradição pode acabar por se diferenciar grandemente da sua composição inicial (quer pelo número de mudanças, quer pela consistência dos conceitos alterados), levando dessa maneira a consolidação de uma tradição nova que imediatamente rivaliza com a tradição de origem.

\section{TRADIÇÃO MENDELIANA}

A história do religioso e cientista Gregor Mendel nos mostra os desafios enfrentados até que uma nova tradição de investigação seja implementada, uma vez que sua consolidação efetiva deu-se somente 30 anos após sua criação. Examinando este período extremamente longo entre a criação e a adoção dessa tradição é possível perceber o papel exercido pela formação diferenciada deste pesquisador, o que lhe permitiu entrar em disputa com a tradição darwinista, a qual já era bem promissora por resolver mais problemas e apresentar maior resultado de progresso. Percebe-se também a importância de uma audiência primária, que no seu caso era muito difusa e provavelmente pouco conseguiria se identificar com as inovações que ele se propunha a implementar.

\section{FORMAÇÃO DO PESQUISADOR GREGOR MENDEL}

Johannes Mendel (que adotou o nome de Gregor quando iniciou sua vida religiosa) nasceu no ano de 1822, em uma família de horticultores de Heinzendorf bei Odrau, uma pequena vila dentro do Império Austro-Húngaro. Desde sua infância lidou com o cultivo de plantas e o uso de técnicas de 
enxertia e hibridização. Durante seu período de formação enfrentou inúmeros desafios, incluindo a enfermidade e posterior morte de seu pai, limitações financeiras que consumiriam tanto seu dote quanto o de uma de suas irmãs, e longos períodos de fome e doença. Foram tais desafios que teriam levado Mendel a se tornar professor primário e matricular-se no curso gratuito de Filosofia da Universidade de Olmütz, que lhe permitiu candidatar-se ao sacerdócio. Foi em meio a este contexto de desafios e altíssimos investimentos familiares que Gregor Mendel passou a aproveitar, tanto quanto possível, as oportunidades de aprendizado que lhe eram apresentadas. Uma vez ingresso na universidade estudou Filosofia, Latim, Filologia Grega, Matemática, Física, Religiões, História e História Natural (Freire-Maia, 1995).

Após o término dos seus estudos universitários Mendel entrou no mosteiro de Altbrünn na posição de noviço, por influência de seu professor de física frei Friedrich Franz. Findo o seu noviciado iniciou os seus estudos teológicos, bem como cursos de agricultura, arboricultura e vinicultura. Assumiu poucos anos depois a posição de instrutor adjunto do ginásio de Znaim, posição que posteriormente veio a exigir que prestasse exames na universidade de Viena, sendo aprovado na disciplina de Física, mas reprovado em Geologia e Zoologia por "não atender à terminologia técnica e por expressar ideias pessoais não condizentes com a ciência tradicional" (Freire-Maia, 1995, p.3).

\section{INÍCIO DA TRADIÇÃO DE INVESTIGAÇÃO MENDELIANA}

$\mathrm{O}$ argumento utilizado na primeira das duas reprovações de Gregor Mendel na Universidade de Viena, bem como sua história de vida, dá fortes indícios de como se desenvolveu sua tradição de investigação. Suas condições de vida o obrigaram a apostar em uma formação tão ampla quanto possível, na qual conheceu bem tanto os métodos de trabalho com a terra quanto as metodologias da Física, saberes que grandemente moldariam seus trabalhos sobre hereditariedade.

Não fica claro sob que aspectos a "terminologia técnica" e as "ideias pessoais" de Mendel foram "não condizentes com a ciência tradicional". Mas o fato é que estas posições se diferenciavam da tradição de seus examinadores, sendo fortes o suficiente para perdurar por mais três anos de formação na Universidade de Viena (onde cursou Zoologia, Botânica, Paleontologia, Física e Matemática), resistirem a uma nova reprovação em 1853 (Freire-Maia, 1995) e serem publicadas em 1865, como "o único caminho certo pelo qual possamos alcançar finalmente a solução de um problema cuja importância para a evolução das formas orgânicas nunca poderá ser subestimada" (Mendel, [1865](1995), p.54).

A oposição enfrentada por Mendel torna-se mais clara ao se tomar consciência de que o trabalho apresentado por ele não tinha como objetivo principal o estudo de híbridos mas, como expresso na introdução de seu trabalho, a compreensão do próprio processo evolutivo, manifesto pela 
eminente necessidade de "uma lei de aplicação geral que governe a formação e desenvolvimento dos híbridos" (Mendel, [1865](1995), p.53). Ele tornou claro que o papel dos híbridos era de ser um meio de aproximar-se destas leis e não o fim de sua busca. Essa aproximação só foi atingida devido a sua familiaridade com métodos estatísticos inexplorados por seus contemporâneos das ciências naturais (Batisteti et al., 2010), incluindo aqueles que lhe serviram de referencial, tais como Gartnër, Herbert, Kölreuter e, de forma indireta, o próprio Darwin. Fazendo uso em seu trabalho de fecundação em cativeiro de mais de dez mil plantas de subespécies ou espécies distintas de ervilhas (Pisum) (Mendel, [1865](1995)). Isso tudo apenas 5 anos após a publicação de "A origem das espécies", diante de um público que, tal como Darwin e Kölreuter, acreditava na baixa fecundidade dos híbridos e espécies em cativeiro (Darwin, [1859](2007)).

Não foi por acaso que o trabalho de Mendel teve pouca repercussão ao ser apresentado, uma vez que sua tradição simplesmente não contava com a "audiência primária", como proposta por Laudan (1986), pois seu trabalho de hibridização não interessou nem para os hibridizadores (por se tratar de cruzamento de variedades semelhantes) e nem para os darwinistas (que estavam pouco propensos a crer que espécies vegetais pudessem se transformar uma na outra em poucas gerações) (Bizzo, 2008). Além disso, a própria linguagem matemática característica de sua investigação pode ter sido um empecilho para entendimento dos que leram sua obra (Batisteti et al., 2010).

A partir da perspectiva de Laudan é possível perceber que a formação de Mendel foi singular em relação a de outros pesquisadores, já que se viu obrigado a trabalhar desde o início com muitas tradições distintas. Um conjunto dessas diz respeito as características ontológicas de sua prática, presentes na parte botânica de sua tese representada, segundo Leite et al. (2001), por uma corrente de hibridizadores, formada por Lineu, Kölreuter, Gärtner e Naudin, interessados na produção de novas espécies através de hibridização; e outra corrente de cultivadores, composta por Knight e Sageret, cujo interesse era o melhoramento da qualidade das plantas e animais.

Já no aspecto evolutivo de seu trabalho temos como influência o próprio darwinismo, uma vez que sua dissertação tinha expressamente por fim tratar da questão levantada por Darwin de que "são geralmente desconhecidas as leis que regulam a hereditariedade" (Darwin, [1959](2007), p.78). Uma última tradição que fortemente influenciou Mendel, desta vez pelo viés metodológico, foi a da Física, na qual aprendeu a usar métodos estatísticos para a análise de dados (Leite et al. 2001).

Uma outra diferença entre a tradição de Mendel e a de seus contemporâneos diz respeito ao método que cada um destes usava. Enquanto os hibridizadores e darwinistas utilizavam predominantemente um método indutivo (Freire-Maia, 1995) (caracterizado pela observação dos fatos empíricos e posteriormente pela formulação de enunciados generalizáveis [Popper, 2007]), Mendel seguia uma linha mais racionalista e hipotético-dedutiva. O que é perfeitamente 
comprovável, seja porque "quando começou as suas experiências de hibridação, Mendel já tinha formulado uma hipótese teórica que iria procurar confirmar” (Veloso, 2003, p.116), ou porque só a seleção das sementes a serem utilizadas durou cerca de 2 anos, durante os quais ele pôde escolher as que melhor se comportavam de modo a corroboração de sua hipótese (Mendel, [1865](1995)).

\section{TRADIÇÕES RIVAIS}

A tradição mendeliana surgiu na época em que a darwiniana estava se consolidando fortemente, pois o problema da "origem das espécies", por ela resolvida, era uma questão já antiga, e que de forma incipiente se manifestava nos estudos de Cuvier (1769-1832) sobre os catastrofismos e anatomia comparada, assim como nos estudos de Lamarck (1744-1829) sobre a transmissão de caracteres adquiridos. Estes cientistas, assim como inúmeros outros célebres ou desconhecidos, vinham a muito tempo encontrando indícios da extinção de espécies (Bryson, 2005). Coube a Darwin a árdua tarefa de, com o auxílio de inumeráveis colaboradores, juntar o material que lhe permitiria propor uma teoria que justificasse a grande diversidade de espécies atuais e pretéritas. A consolidação de sua tradição era tão ansiada que, por um mero detalhe não foi apresentada primeiro por outro pesquisador (Alfred Russel Wallace) que, apesar de ter menos resultados do que Darwin, atingiu as mesmas conclusões que este sobre a seleção natural.

Com o seu estabelecimento, a tradição mendeliana passou a rivalizar-se ao darwinismo, gerando diversos problemas anômalos para esta última tradição, entre os quais a fecundidade normal em híbridos e plantas domesticadas, a previsibilidade da hibridização, a permanência de características deletérias nas espécies e a própria origem das características fenotípicas. Apesar das vantagens e potencial da teoria mendeliana, esta não foi aceita em sua época, provavelmente por não ser tão progressista ou não resolver tão bem aos problemas quanto sua rival.

Analisando-se a teoria darwiniana, sob o ponto de vista da resolução de problemas de Laudan, torna-se mais fácil compreender sua força e aceitação, bem como sua primazia em relação ao mendelismo. Considerando o darwinismo apenas pela obra "A origem das espécies" e a história por trás de sua publicação pode-se tirar algumas conclusões: em primeiro lugar, a questão da origem das espécies era um problema anômalo extremamente relevante para a época, que foi de certa forma resolvido por Darwin; em segundo lugar, o darwinismo, ao ser lançado, já contava (ao menos parcialmente) de modo automático com a audiência primária de quase todo o corpo de cientistas com quem Darwin se correspondia; em terceiro lugar, o trabalho de Darwin era extremamente robusto, sob o ponto de vista de ser apoiado por evidências geológicas, paleontológicas, botânicas, zoológicas, geográficas e comportamentais; em quarto lugar, desde sua formulação até ser lançada, Darwin dispôs de um intervalo de 20 anos para resolver os problemas internos, empíricos e conceituais de sua 
teoria (Darwin, [1859](2007)); em quinto lugar, o darwinismo foi fundado no centro cultural da época (Bryson, 2005), por alguém já renomado que se relacionava com pessoas também renomadas (Leakey, 2007); e por fim, as idéias de Darwin permitiam que se pensasse nas espécies sem que com isso houvesse algum vinculo obrigatório entre ciência e religião.

O mendelismo, por sua vez, foi tratado como uma tradição que visava resolver um problema considerado mais agrícola do que científico. Apresentado em um povoado que a pouco tempo se livrara da influência feudal, não como uma lei geral, mas na condição de "uma lei válida para Pisum" (Mendel, [1865](1995) p.89), o que restringiu desta forma a robusteza da tradição. Quanto a audiência primária, o trabalho de Mendel teve pouca repercussão, possivelmente por não encontrar quem se identificasse com seus resultados. Por fim o prestígio de Gregor Mendel era tão baixo que pesquisadores como Karl W. Naugeli (1884) e Hugo de Vries (em seu primeiro trabalho em 1900), apesar de usarem sua obra, não a citam em momento algum, o que Ives Delage também não fez em seu livro "A hereditariedade e os grandes problemas da Biologia Geral”, datado de 1903 (FreiraMaia, 1995).

\section{REDESCOBERTA}

A redescoberta das conclusões de Mendel só aconteceu 30 anos após a publicação de seus resultados. Ocorreu de maneira independente durante o ano de 1900 através de três pesquisadores, o primeiro deles foi Hugo de Vries, que apesar de só citar o nome de Mendel em seu segundo trabalho desde o primeiro já utilizara as nomenclaturas "dominante" e "recessivo" ao se referir as características herdadas. O segundo redescobridor foi Karl Correns, o qual chegou aos mesmos resultados que Mendel ao utilizar variáveis de milho e ervilha, comentando seus resultados logo após receber o primeiro trabalho de Vries. Por fim o último redescobridor foi Erich Von Tschermak, este fazia trabalhos com ervilhas chegando a resultados também muito semelhantes aos de Mendel sendo obrigado, porém, ao ter contato com a obra desse, a reconhecer que os experimentos do abade eram bem mais robustos dos que os seus. Tanto Correns, quanto Tschermak apontaram o óbvio conhecimento prévio da obra de Mendel por parte de Vries (Freire-Maia 1995).

Seria muita ingenuidade atribuir ao acaso essas três redescobertas concomitantes. Ao que parece a metodologia das ciências naturais estava gradualmente se voltando para as contribuições estatísticas, utilizadas décadas antes nas pesquisas de Mendel. Esta gradual mudança metodológica; bem como avanços tecnológicos, como a microscopia, seriam os responsáveis pelo desenvolvimento de uma tradição que aceitasse as descobertas já realizadas a muito tempo por Mendel (Veloso, 2003). 


\section{NEODARWINISMO}

Apesar da redescoberta das leis de Mendel e da já consolidada teoria de Darwin, diversas questões permaneceram em aberto para uma ou outra destas correntes teóricas. Para o darwinismo permanecia sem solução o aparecimento de novas características, o papel do ambiente e das forças internas, o saltacionismo das mudanças e o caráter linear da evolução (Sanchez, 2020). Enquanto o mendelismo, apesar de explicar a transmissão e o ressurgimento de características, não explicava a origem destas.

Tais problemas só foram efetivamente resolvidos após 30 anos de conflitos entre as duas tradições. Neste período, as tradições passaram por mudanças tais que levaram alguns historiadores a sugerir que o próprio Mendel não era mendeliano, no sentido atribuído ao termo hoje (Allen, 2003). Tais alterações foram graduais, inicialmente introduzindo-se o conceito de "mutações", atingido através das observações de De Vries das características que surgiam espontaneamente. Posteriormente, formulou-se o termo "Genética" e foi feita uma clara separação entre os conceitos de fenótipo e genótipo. Estes avanços, partidos da linha mendeliana, trouxeram à esta algum status quanto a sua capacidade explicativa, além de incitarem pesquisadores como Thomas Morgan a investigar a tradição, e desenvolver estudos, desta vez com Drosophila melanogaster (mosca de fruta), demonstrando que mutações podiam não apenas surgir de maneira espontânea, como também ser herdada de acordo com as leis mendelianas, podendo-se expandir estas leis também as heranças ligadas ao cromossomo sexual. Avançando ainda mais em seus estudos Morgan descobriu que os genes podiam se expressar em conjunto, ou ainda sofrerem recombinação por crossing-over. Em paralelo Fred Griffith e outros cientistas traziam avanços sobre o papel do ADN e suas propriedades na hereditariedade. Todos estes avanços, expressos pela resolução de problemas relevantes, tornaram a tradição mendeliana uma opção progressista capaz de rivalizar com o darwinismo (Veloso, 2003).

Neste período tanto a tradição criada por Mendel quanto a criada por Darwin, cada uma a sua maneira, estava resolvendo problemas relevantes e ao mesmo tempo criando anomalias para sua rival, até que na década de 1940 sentiu-se a necessidade de uma teoria integrativa, que respondesse as questões explicadas tanto por uma quanto pela outra tradição (Freire-Maia, 1995). Estabeleceu-se assim, por meio de sucessivas teorias ad hoc, seja em relação ao darwinismo ou ao mendelismo, a teoria sintética ou neodarwinismo, fundamentada na "seleção natural" de Darwin e Wallace, e na hereditariedade proposta por Mendel. Assim como na colaboração dos que compartilhavam as ideias destes: como no surgimento de novas características por mutações, como proposto por Vries e aprimorado por outros pesquisadores; na recombinação e herdabilidade proposta por Morgan; na possibilidade de evolução por saltacionismo de William Bateson; nos cálculos de freqüência genotípica estabelecidos por Hardy e Weinberg; na posição de Fisher de que a maioria das 
características se deve a combinação do efeito de vários genes; na deriva gênica proposta por Wrigh (Sanchez, 2020). Todas estas colaborações foram então sistematizadas na forma de uma nova tradição, que levava em conta o que cada uma delas conseguia resolver, de modo a eliminar uma infinidade de anomalias, formando assim uma tradição forte que, apesar de utilizar os conhecimentos dos mais destacados cientistas de quase um século, carregou em seu nome apenas a referência do mais célebre de seus colaboradores, Charles Darwin.

\section{CONCLUSÃO}

Os experimentos de Mendel representaram um grande avanço para a biologia, percebendo-se em seus estudos a importância de uma formação abrangente, para se conseguir enxergar além da tradição dominante. A repercussão de seus resultados demonstra também a influência que a audiência primária tem na aceitação de uma tradição, podendo relegar uma teoria a um estado de esquecimento de mais de 30 anos, mesmo que esta seja perfeitamente corroborável e possua um gigantesco potencial progressista. A história de Mendel aponta também uma questão adicional, a importância dos problemas conceituais nas ciências, demonstrado pela conclusão generalizável decorrente de seu experimento com o gênero Pisum, cuja solução abriu espaço para um novo e abrangente campo de pesquisa, conhecido hoje como genética.

Por fim a proposição de análise de Laudan, com o foco na capacidade de resolução de problemas, nos demonstra porque uma teoria com tanto potencial quanto o mendelismo foi obrigada a ceder espaço na resolução de problemas para o darwinismo, cujo avanço e capacidade explicativa tornaram-na a mais racional a ser seguida por um longo tempo. Explica também a racionalidade de se adotar o mendelismo, quando este passou a ser mais progressivo e gerar menos anomalias que o darwinismo. 


\section{REFERÊNCIAS}

ALLEN, Garland E. Mendel and modern genetics: the legacy for today. Endeavour. v.27, n.2, jun 2003.

BATISTETI, Caroline Belotto; ARAÚJO, Elaine Sandra Nabuco de; CALUZI, João José. O trabalho de Mendel: um caso de prematuridade científica?. Filosofia e História da Biologia. São Paulo, v. 5, n. 1 p. 35-53, 2010.

BIZZO, Nélio. A teoria genética de Charles Darwin e sua oposição ao mendelismo. Filosofia e História da Biologia. São Paulo, v. 3, p. 317-333, 2008.

BRYSON, Bill. Breve história de quase tudo. São Paulo: Schwarcz, 2005.

DARWIN, Charles. A Origem das Espécies. São Paulo: Martin Claret, 2004 [1859].

FREIRE-MAIA, N. Gregor Mendel: Vida e Obra. T. A. Queiroz, São Paulo. 1995.

LAUDAN, Larry. El progreso y sus problemas: Hacia una teoría Del crecimiento científico. Madri: Ediciones Encuentro, 1986.

LEAKEY, Richard. A Origem das Espécies. In. DARWIN, Charles. A Origem das Espécies. São Paulo: Martin Claret, 2004.

LEITE, Raquel Crosara Maia; FERRARI, Nadir; DELIZOICOV, Demétrio. A História das Leis de Mendel na Perspectiva Fleckiana. Revista Brasileira de Pesquisa em Educação em Ciências. v. 1, n.2, pag. 97-108 - Maio/Agosto 2001.

MENDEL, Gregor. Experiências sobre hibridosvegetais. In: FREIRE-MAIA, N. Gregor Mendel: Vida e Obra. T. A. Queiroz, São Paulo. 1995 [1865].

POPPER, Karl. A Lógica da Pesquisa Científica. São Paulo: Cultrix, 2007

SÁNCHEZ, Antonio León. Los problemas de la evolución III La Teoría Sintética. Disponível em: http://cienciarazonyfe.com/assets/archivos/articulos1478538124.pdf. Acesso em: 03 set 2020.

VELOSO, A. J. Barros. Das ervilheiras de Mendel à dupla hélice de Watson e Crick. Medicina

Interna. Lisboa. v.10. n.3 Jul-set. 2003 